\title{
FORMULATION AND IN VIVO EVALUATION OF SELF-NANOEMULSIFYING DRUG DELIVERY SYSTEM OF RAMIPRIL IN WISTAR RATS
}

\author{
NALLAPU JAYAPAL*, YAMSANI VAMSHI VISHNU
}

Department of Pharmacy, Mewar University, Chittorgarh, Rajasthan, India. Email: jayapalnallapu14@gmail.com

Received: 08 May 2021, Revised and Accepted: 04 June 2021

\begin{abstract}
Objective: The aim was to formulate and evaluate self-nanoemulsifying drug delivery systems (SNEDDS) of ramipril, an antihypertensive drug to improve the solubility and bioavailability.

Methods: Based on solubility studies oil phase (Sefsol 218), surfactant (Acrysol EL135), and cosurfactant (Transcutol P), respectively, were selected to prepare SNEDDS. Ramipril SNEDDS optimized employing box-Behnken design through the study of factors. All formulations were evaluated for particle size, zeta potential (ZP), polydispersity index (PDI), entrapment efficiency (EE), drug content, and in vitro drug release. The optimized formulation was characterized for Fourier transform infrared (FTIR), scanning electron microscopy (SEM), stability studies, and pharmacokinetic study.
\end{abstract}

Results: The mean particle size, PDI, ZP, EE, content uniformity, and in vitro drug release profile of optimized ramipril-loaded SNEDDS (RF14) were found to be $75.3 \pm 2.21 \mathrm{~nm}, 0.126 \pm 0.05,-24.4 \pm 5.78 \mathrm{mV}, 98.74 \pm 1.97 \%, 99.52 \pm 1.67 \%$, and $98.65 \pm 1.73 \%$, respectively. FTIR studies revealed that there is no incompatibility between drug and excipients, SEM images exhibited nanoparticles to be more porous and in spherical shape. Stability studies indicated formulation was stable for 6 months. In vivo studies were conducted for optimized formulation RF14, the $\mathrm{T}_{\text {max }}$ was found to be $0.5 \pm 0.62$ and $0.5 \pm 0.95 \mathrm{~h}$ for the optimized and commercial formulations respectively, while $\mathrm{C}_{\max }$ was $25.16 \pm 1.73 \mathrm{ng} / \mathrm{mL}$ was significant ( $<<0.05$ ) as compared to the ramipril pure drug $8.02 \pm 0.086 \mathrm{ng} / \mathrm{mL}$. AUC0-t of the SNEDDS formulation was higher $355.49 \pm 1.76 \mathrm{ng}$ h/ml compared to pure drug $116.57 \pm 1.64 \mathrm{ng} \mathrm{h} / \mathrm{ml}$ indicated higher amount of drug concentration in blood proving better systemic absorption of ramipril from SNEDDS formulation as compared to the pure drug.

Conclusion: It is concluded from the results that ramipril was successfully formulated into SNEDDS with higher concentration with fast action.

Keywords: Self-nanoemulsifying drug delivery system, Ramipril, Solubility, Ternary phase diagram, In vivo bioavailability studies.

(C) 2021 The Authors. Published by Innovare Academic Sciences Pvt Ltd. This is an open access article under the CC BY license (http://creativecommons.org/ licenses/by/4.0/) DOI: http://dx.doi.org/10.22159/ajpcr.2021v14i7.42003. Journal homepage: https://innovareacademics.in/journals/index.php/ajpcr

\section{INTRODUCTION}

The Class II to Class IV drugs of biopharmaceutical classification system suffering with poor water solubility led to the lower intestinal absorption and lower bioavailability. Solubilizing poor water-soluble drugs is a major challenge in pharmaceutical research. Lipid-based drug formulations increase the relative solubility of drugs in GI track by enhancing absorption. Self-nanoemulsifying drug delivery systems (SNEDDS) lipid-based formulations are most promising technology in drug delivery [1].

SNEDDS is defined as pre-concentrate containing a mixture of drug, surfactants, oil, and cosurfactant. The smaller size of SNEDDS improves drug dissolution by increasing area for drug release, absorption, and by promoting lymphatic transport of the drug. SNEDDS formulation is used for increasing the solubility, oral bioavailability, and permeability of drug. It also protects the drug from hostile environment in GI track and is used for selective GI targeting drug delivery [2]. They have particle size ranging from nanometers to few microns. Based on particle size, they are further classified into SMEDDS and SNEDDS. SMEDDS forms microemulsions consisting of oil droplet size ranging between 100 and $200 \mathrm{~nm}$. SNEDDS contains the droplets whose size is $<100 \mathrm{~nm}$.

Ramipril a potent antihypertensive drug, belonging to the category of ACE inhibitor is widely used in the treatment of high blood pressure and congestive heart failure. Ramipril is highly lipophilic poorly water soluble (3.5 mg/l) drug belonging to BCS Class II. Ramipril, being poorly water soluble resulted in erratic absorption in gastrointestinal tract (GIT) which further led to poor bioavailability (about 28\%). It also showed high first pass metabolism. Hence, increasing the aqueous solubility and dissolution of ramipril in GIT is of therapeutic importance. The main intention behind choosing SNEDDS formulation for ramipril drug was that lipid-based formulations enhance the solubility of lipophilic drugs that may further enhance the dissolution rate and absorption in the GIT. Hence, the main objective of current research work was to develop SNEDDS of ramipril to enhance the solubility of the drug [3].

\section{MATERIALS AND METHODS}

\section{Materials}

Ramipril is a gift sample from Hetero Labs Limited, Hyderabad, India. Oils - (Capmul MCM, Captex 355, Capmul PG8, Capryol 90, Imwitor 742, IPM, Labrafil M2, Labrafac CC, Labrafac Lipophile WL 1349, Maisine 35-1, Miglyol 812, Paceol, Sefsol 218, Olive oil, Oleic acid, and Castor oil) were purchased from local market. Surfactants - (Acrysol K140, Acrysol EL135, Acconon E, Acconon CC400, Acconon Sorb20, Capmul GMO 50, Caprol PGE 860, Caprol ET, Cremophor EL, Cremophor RH40, Gelucire 44/14, Labrasol, Solutol HS15, Tween 80, and Tween 20 and Triton-9100). Co-surfactants - (Capmul MCMC8, Lauroglycol 90, PEG 400, PG, EG, PlurolOleique CC497, Triacetin, Transcutol P, Propylene Glycol), polymers such as Microcrystalline cellulose, HPMC E50LV, HPMC AS, and Poloxamer 407 purchased from Gattefosse, Mumbai.

\section{Methods}

Selection of oil (solubility studies)

The solubility's of Ramipril were measured in numerous oils individually by shake flask method at constant temperature as mentioned in 
reported procedure. The amount of drug in all samples was determined by their subsequent dilution with suitable solvent using double beam UV Visible spectrophotometer against blank at $210 \mathrm{~nm}$. The study was repeated in triplicate and their mean values were recorded [4].

\section{Selection of surfactant (emulsification study)}

The emulsification ability of various surfactants was screened to find out the most suitable surfactant system for the selected oily phase. Sixteen non-ionic were screened to evaluate their propensity to emulsify optimized oil phase. The study was performed according to the reported procedure in triplicates and the average values were recorded [4].

\section{Selection of co surfactant (emulsification study)}

The cosurfactants have ability to improve the nanoemulsification efficiency. Eight cosurfactants were screened for their potential to assist previously selected surfactant in terms of emulsification of respective oil phase as per referred procedure [5]

\section{Pseudo-ternary phase diagram study}

On the basis of the solubility study of drug, oil, surfactant, and cosurfactant were selected. Distilled water was used as an aqueous phase for phase diagram study. Surfactant and cosurfactant $\left(\mathrm{S}_{\text {mix }}\right)$ were mixed in different weights ratios $(1: 1,1: 2,1: 3,2: 1,3: 1$, and 4:1). These $\mathrm{S}_{\text {mix }}$ ratios were chosen in increasing concentration of surfactant with respect to cosurfactant, and increasing concentration of cosurfactant with respect to surfactant. For each phase diagram, oil and specific $S_{\text {mix }}$ ratio were mixed in different ratios $0.5: 9.5,1: 9,1.5: 8.5,2: 8,2.5: 7.5$, 3:7, 3.5:6.5, 4:6, 4.5:5.5, 5:5, 5.5:4.5, 6:4, 6.5:3.5, 7:3, 7.5:2.5, 8:2, 8.5:1.5, $9: 1$,and $9.5: 0.5$ ). Pseudo-ternary phase diagrams were developed using aqueous titration method [6].

\section{Formulation and development of ramipril loaded SNEDDS Preparation of ramipril loaded SNEDDS}

The Ramipril loaded SNEDDS were prepared by mixing oil phase (Sefsol 218), surfactant (Acrysol EL135), and cosurfactant (Transcutol P) and warming it at $40^{\circ} \mathrm{C}$, then Ramipril was added to the mixture and vortexed to facilitate the uniform dispersion of Ramipril. The mixture was then allowed to equilibrate at room temperature. Seventeen such experiments were carried out according to the experimental design with varying concentration of oil, surfactant, and cosurfactant, with the final Ramipril loading equivalent to $2 \mathrm{mg} / \mathrm{gm}$. Ramipril $(10 \mathrm{mg})$ added to oil into the glass vial and heated in hot water bath at $40^{\circ} \mathrm{C}$ until drug solubilized. Then, to this oily mixture was added surfactant and cosurfactant and sonicated for $60 \mathrm{~min}$. The prepared Ramipril loaded SNEDDS were filled into size 0 gelatin capsule shells [7]

\section{Experimental design}

Box-Behnken experiment design (box-Behnken design [BBD])

A 33 BBD employed for optimizing the main, interaction, and quadratic effects of formulation components on characteristics of SNEDDS. Seventeen experiments run randomly for chosen independent variables that include five repetitions at center (asterisk-marked) obtained from three factors, three-level BBD, and their subsequent responses noted 14. The variables that were chosen as dependent and independent are specified in Tables 1 and 2 [8].

The BBD matrix obtained using Design Expert ${ }^{\circledR}$ software (Version7.0, Stat-Ease Inc., Silicon Valley, CA, USA), the second-order quadratic equations are as:

$$
\begin{aligned}
& Y=\beta_{1}+\beta_{1} X_{1}+\beta_{2} X_{2}+\beta_{3} X_{3}+\beta_{4} X_{1} X_{2}+\beta_{5} X_{2} X_{3}+\beta_{6} X_{1} X_{3}+\beta_{7} \beta_{1}^{2}+ \\
& \beta_{8} \beta_{2}^{2}+\beta_{9} \beta_{3}^{2}
\end{aligned}
$$

$\mathrm{Y}$ - Level of the measured response

$\beta 0$ - intercept

$\beta 1$ to $\beta 9$ - regression coefficient

$\mathrm{X} 1, \mathrm{X} 2$, and X3 - main effects
$\mathrm{X} 1 \mathrm{X} 2, \mathrm{X} 2 \mathrm{X} 3$, and X1X3 - interaction between the main effects. $\mathrm{X} 12, \mathrm{X} 22$, and X32 - quadratic terms of independent variables.

\section{Optimizations using the desirability function}

In the present study, all three responses were simultaneously optimized by a desirability function that uses the numerical optimization method introduced by Derringer and Suich in the Design-Expert software (Version8.0, Stat-Ease Inc., Silicon Valley, CA, USA).

\section{Characterization of SNEDDS}

Developed Ramipril SNEDDSs were physicochemically evaluated in terms of droplet diameter, polydispersity index (PI), zeta potential (ZP), entrapment efficiency (EE), drug content, and cumulative \% drug release as per reported procedures [9-12].

\section{In vitro release studies of ramipril SNEDDS}

Drug release tests on each batch of the SNEDDS were carried out using a USP I dissolution rate test apparatus at a stirring speed of $50 \mathrm{rpm}$ and temperature of $37 \pm 0.5^{\circ} \mathrm{C}$. An amount of the SNEDDS equivalent to $40 \mathrm{mg}$ of drug was filled in a hard gelatin capsule (Size no.0) and was placed in the dissolution medium containing $900 \mathrm{~mL}$ of phosphate buffer $\mathrm{pH}$ 7.4. A $5 \mathrm{~mL}$ quantity of the dissolution medium was sampled at predetermined time intervals of every $10 \mathrm{~min}$ up to $60 \mathrm{~min}$ and fresh dissolution medium was simultaneously used to replenish the dissolution medium on each occasion to keep the volume constant. The sample was filtered and was analyzed using UV spectrophotometrically at $210 \mathrm{~nm}$ [13]

\section{Pharmacokinetic studies of ramipril \\ Animal preparation}

Healthy Wistar rats were (Weighing 150-180 g) selected for this study, all the animals were healthy during the period of the experiment. All efforts were made to maintain the animals under controlled environmental conditions (Temperature $250^{\circ} \mathrm{C}$, Relative Humidity $45 \%$ and $12 \mathrm{~h}$ alternate light and dark cycle) with $100 \%$ fresh air exchange in animal rooms, uninterrupted power, and water supply. Rats were fed with standard diet and water ad libitum. The protocol of animal study was approved by the institutional animal ethics committee (IAEC NO: 1447/PO/Re/S/11/CPCSEA/16/A)

\section{Study design}

Rats were divided in to two groups at random each group containing six rats. The treatments as given below were administered to the rabbits. The rats were fasted for $24 \mathrm{~h}$ prior to the experiments. After $4 \mathrm{~h}$ of dosing, foods were reoffered. First group was administered with pure Ramipril (as such) made suspension with 0.5\% methocel and second group was administered Prepared Ramipril optimized SNEDDS diluted in $0.5 \%$ methocel by oral route at a dose of $1.17 \mathrm{mg}[14,15]$.

Determination of Ramipril in Rabbit plasma by HPLC method Sheseido column C18 column $250 \mathrm{~mm} \times 4.6 \mathrm{~mm}, 5 \mu$ diameter was used for separation. The mobile phase containing $0.2 \%$ orthophosphoric acid: acetonitrile in the ratio of $50: 50(\mathrm{v} / \mathrm{v})$ was delivered at a flow rate $0.6 \mathrm{ml} / \mathrm{min}$ and the elution was monitored at $205 \mathrm{~nm}$. Injection volume

Table 1: List of dependent and independent variables in in box-

\begin{tabular}{|c|c|c|c|c|c|}
\hline \multicolumn{3}{|c|}{ Independent variables } & \multicolumn{3}{|c|}{ Levels } \\
\hline Variable & Name & Units & $\begin{array}{l}\text { Low } \\
(-1)\end{array}$ & $\begin{array}{l}\text { Middle } \\
\text { (0) }\end{array}$ & $\begin{array}{l}\text { High } \\
(+1)\end{array}$ \\
\hline A & Amount of Sefsol 218 & $\mathrm{mg}$ & 10 & 20 & 30 \\
\hline B & Amount of Acrysol EL135 & $\mathrm{mg}$ & 20 & 30 & 40 \\
\hline $\mathrm{C}$ & Amount of Transcutol P & $\mathrm{mg}$ & 10 & 20 & 30 \\
\hline \multicolumn{3}{|c|}{ Dependent variable } & \multicolumn{3}{|l|}{ Goal } \\
\hline Y1 & Droplet size & $\mathrm{nm}$ & \multicolumn{3}{|c|}{ Minimize } \\
\hline Y2 & Zeta potential & $\mathrm{mV}$ & \multicolumn{3}{|c|}{ Minimize } \\
\hline Y3 & Drug release after $60 \mathrm{~min}$ & $\%$ & \multicolumn{3}{|c|}{ Maximize } \\
\hline
\end{tabular}
Behnken design 
Table 2: Box-Behnken design with observed responses

\begin{tabular}{|c|c|c|c|c|c|c|}
\hline Run & $\begin{array}{l}\text { Amount of } \\
\text { Sefsol } 218 \mathrm{Mg}\end{array}$ & $\begin{array}{l}\text { Amount of } \\
\text { Acrysol EL135 }\end{array}$ & $\begin{array}{l}\text { Amount of } \\
\text { Transcutol P }\end{array}$ & $\begin{array}{l}\text { Droplet } \\
\text { size }(\mathrm{nm})\end{array}$ & $\begin{array}{l}\text { Zeta potential } \\
(-\mathrm{mV})\end{array}$ & $\begin{array}{l}\text { Drug release } \\
\text { after } 60 \mathrm{~min}(\%)\end{array}$ \\
\hline 1 & 10 & 20 & 20 & 139.2 & 28.7 & 79.14 \\
\hline 2 & 20 & 20 & 20 & 146.1 & 29.6 & 89.44 \\
\hline 3 & 30 & 40 & 30 & 92.9 & 22.3 & 92.13 \\
\hline 4 & 20 & 40 & 20 & 89.3 & 26.8 & 90.78 \\
\hline 5 & 10 & 30 & 10 & 85.7 & 28.6 & 92.23 \\
\hline 6 & 10 & 20 & 10 & 93.9 & 27.3 & 87.12 \\
\hline 7 & 10 & 30 & 30 & 102.4 & 25.9 & 80.13 \\
\hline 8 & 30 & 30 & 30 & 134.6 & 26.7 & 88.35 \\
\hline 9 & 20 & 20 & 10 & 142.4 & 23.5 & 85.16 \\
\hline 10 & 30 & 40 & 10 & 96.1 & 26.2 & 87.59 \\
\hline 11 & 20 & 20 & 30 & 108.0 & 27.5 & 89.82 \\
\hline 12 & 20 & 20 & 20 & 108.7 & 29.2 & 83.67 \\
\hline 13 & 30 & 30 & 20 & 151.9 & 26.8 & 86.72 \\
\hline 14 & 10 & 40 & 30 & 75.3 & 24.4 & 98.65 \\
\hline 15 & 30 & 40 & 20 & 136.1 & 25.8 & 93.88 \\
\hline 16 & 20 & 30 & 10 & 105.5 & 27.9 & 94.38 \\
\hline 17 & 10 & 30 & 20 & 147.3 & 29.3 & 87.43 \\
\hline
\end{tabular}

was $20 \mu \mathrm{l}$ pressure of $65 \mathrm{~kg} / \mathrm{cm}^{2}$ and temperature $28^{\circ} \mathrm{C}$. Lisinopril was used as an internal standard. The retention times of ramipril and lisinopril were 11.05 and $6.01 \mathrm{~min}$, respectively [16]

\section{Pharmacokinetic analysis}

The pharmacokinetic parameters employed to evaluate were maximum plasma concentration $\left(\mathrm{C}_{\max }\right)$, time to attain $\mathrm{C}_{\max }$, that is, Tmax and $\mathrm{t} 1 / 2$ values, area under plasma concentration-time curve from zero to the last sampling time $(A U C 0-t)$, and area under plasma concentrationtime curve from zero to infinity $(A U C 0-\infty)$. AUCO- $t$ was calculated by the linear trapezoidal rule and $A U C D-\infty$ from the following formula

$\mathrm{AUC} 0-\infty=\mathrm{AUC} 0-\mathrm{t}+\mathrm{Ct} / \mathrm{KE}$

\section{RESULTS AND DISCUSSION}

\section{Percentage drug content and EE}

The \% drug content of all ramipril SNEDDS ranged from $95.13 \pm 1.17$ to $99.52 \pm 1.67 \%$ and the EE varied between $94.35 \pm 1.62$ and $98.74 \pm 1.97 \%$ with maximum value recorded for RF14.

Polydispersity index (PDI) The PDI of all SNEDDSs was significantly varying from 0.126 to 0.158 to as depicted in Table 3 indicating narrow size distribution which reveals the higher stability of Ramipril solid lipid nanoparticles [15].

\section{Selection of formulations from phase diagram}

A pseudo-ternary phase diagram of the investigated quaternary system water/Sefsol 218/Acrysol EL135/Transcutol P is presented in Figs. 1-6. The optimum formulation of SNEDDS contained Sefsol $218(51.11 \%), S_{\text {mix }}(29.13 \%)$, and water $(09.85 \%)$. It can be seen that the largest SNEDDS region is seen when the combination of surfactant and cosurfactant is used. When a co-surfactant is added to the system, it further lowers the interfacial tension between the oil and water interface and also influences the interfacial film curvature, which there by readily deforms around oil droplets. From the phase diagrams, it was observed that as increasing the concentration of surfactant increased the self-emulsifying region. Emulsification region decreased with increasing the concentration of cosurfactant.

\section{Design of experiment}

About 17 experiments performed according to experimental runs generated by 33 Box-Behnken design (BBD) (Table 3).

\section{Droplet size}

The particle size of the SNEDDS was found to be in the range of 75.3$146.1 \mathrm{~nm}$. The mathematical model generated for droplet size (Y1) was found to be significant with F-value of 4439.15 implies the model is significant. The plots are shown in Figs. 7 and 8.
Table 3: Regression Equations of the fitted models

\begin{tabular}{ll}
\hline Response & Equation \\
\hline Droplet Size (Y1) & $73.55+19.89 X 1-16.12 \mathrm{X} 2-2.37 \mathrm{X} 3-$ \\
& $0.51 \mathrm{X} 21+0.16 \mathrm{X} 1 \mathrm{X} 3+12.18 \mathrm{X} 22-1.55 \mathrm{X} 2 \mathrm{X} 3$ \\
& $+1.12 \mathrm{X} 23$ \\
Zeta Potential(Y2) & $15.33+04.19 \mathrm{X} 1+11.72 \mathrm{X} 2+3.28 \mathrm{X} 3+0.39 \mathrm{X} 21-$ \\
& $0.73 \mathrm{X} 1 \mathrm{X} 3-14.66 \mathrm{X} 22-2.47 \mathrm{X} 2 \mathrm{X} 3-3.92 \mathrm{X} 23$ \\
\% Cumulative drug & $92.26-4.12 \mathrm{X} 1+65.77 \mathrm{X} 2-14.53 \mathrm{X} 3+0.29 \mathrm{X} 21$ \\
released (Y3) & $-24.66 \mathrm{X} 1 \mathrm{X} 3+05.15 \mathrm{X} 22-38.47 \mathrm{X} 2 \mathrm{X} 3+2.66 \mathrm{X} 23$ \\
\hline
\end{tabular}

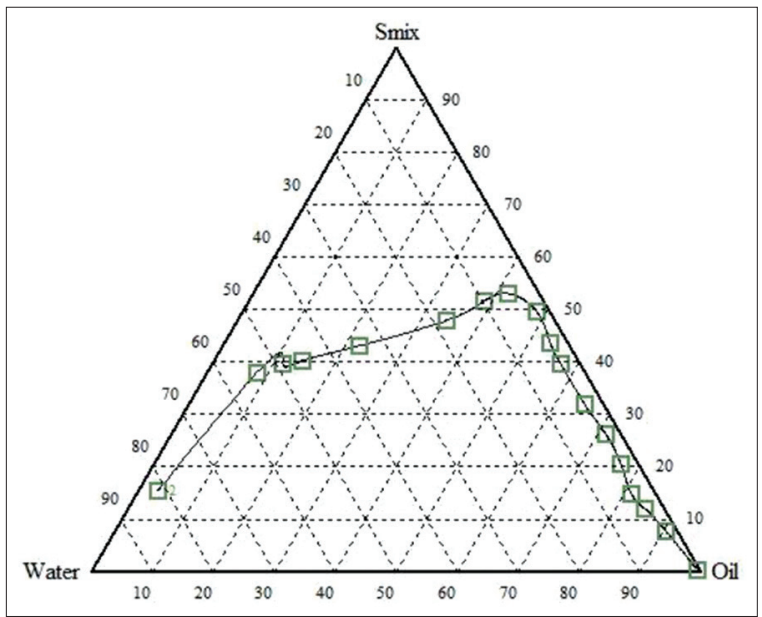

Fig. 1: Pseudo-ternary graph of $S_{\text {mix }}$ ratio1:1

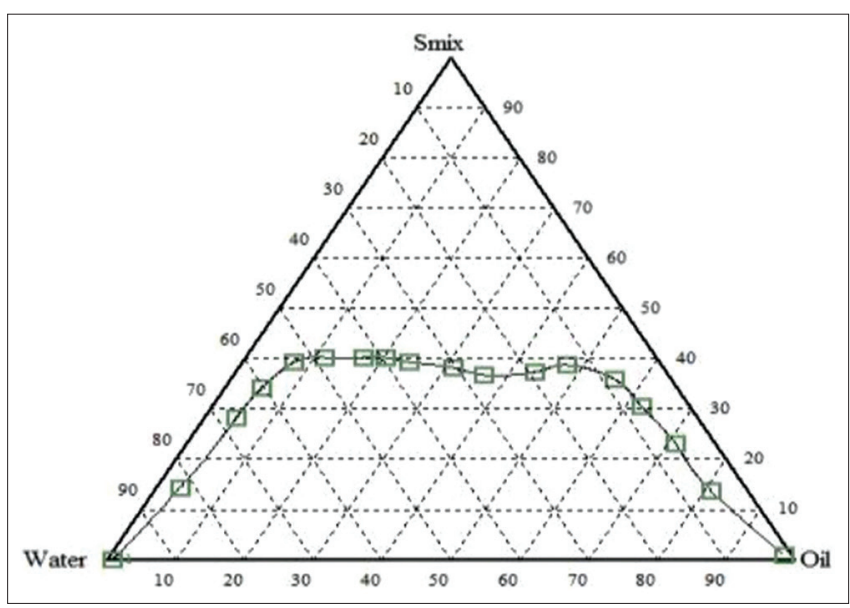

Fig. 2: Pseudo-ternary graph of $S_{\text {mix }}$ ratio1:2 


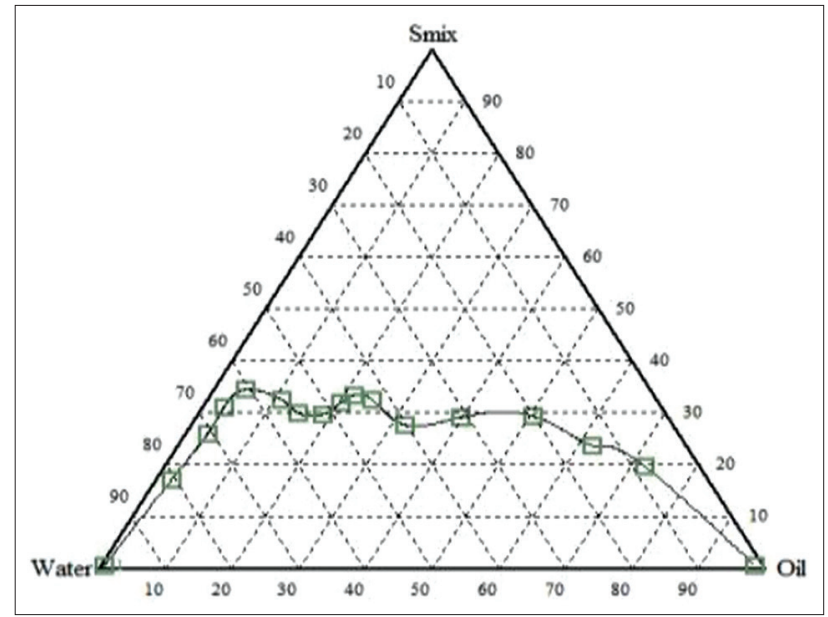

Fig. 3: Pseudo-ternary graph of $S_{\text {mix }}$ ratio1:3

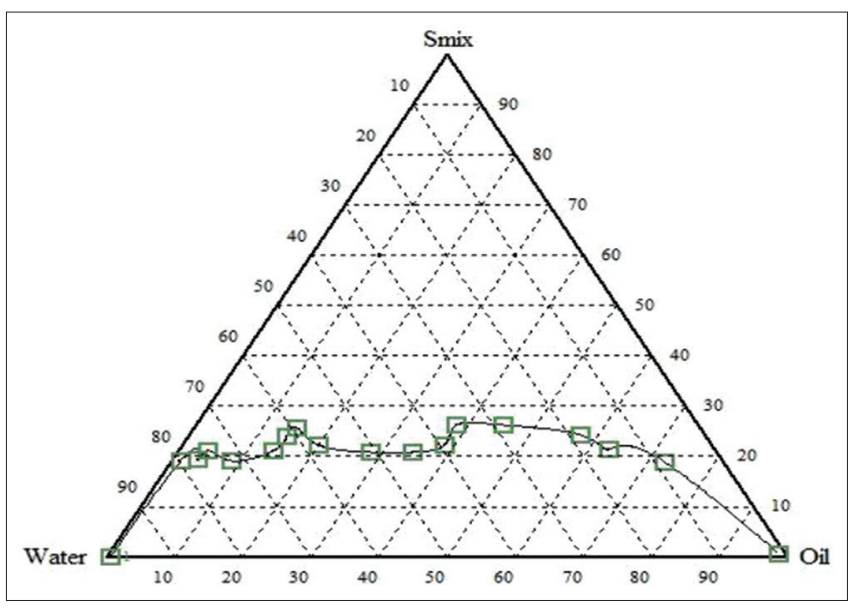

Fig. 4: Pseudo-ternary graph of $S_{\text {mix }}$ ratio2:1

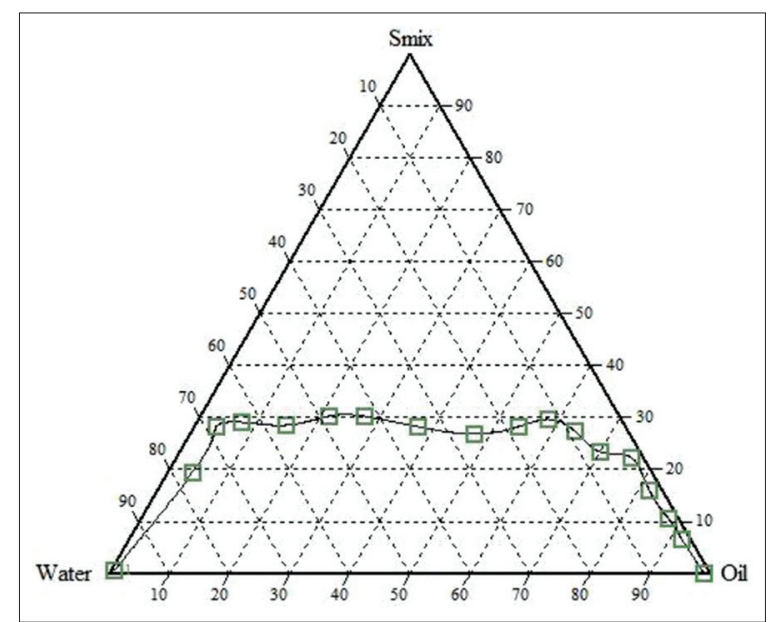

Fig. 5: Pseudo-ternary graph of $S_{\text {mix }}$ ratio3:1

\section{ZP}

The ZP of the SNEDDS was found to be in the range of -24.4--29.6. The quadratic model generated revealed that the amount of AcrysolEL135 and amount of Transcutol P have a significant influence on the ZP. The theoretical (predicted) values and the observed values were in reasonably good agreement as seen. The mathematical model generated for ZP (Y2) was found to be significant with F-value of 0.0128 implies the model is significant. The plots are shown in Figs. 9 and 10

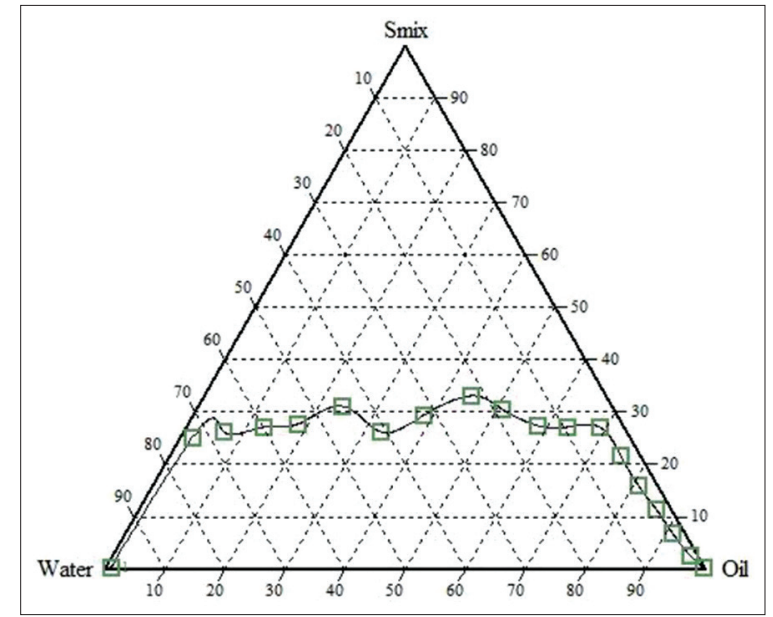

Fig. 6: Pseudo-ternary graph of $S_{\text {mix }}$ ratio 4:1

\section{Cumulative percent drug released}

The Cumulative percent drug release in $60 \mathrm{~min}$ from the SNEDDS was found to be in the range of $79.14-98.65 \%$. The quadratic model generated revealed that the amount of Sefsol 218, amount of AcrysolEL135 and amount of Transcutol P have a significant influence on the droplet size. The theoretical (predicted) values and the observed values were in reasonably good agreement as seen. The mathematical model generated for percent drug release in $60 \mathrm{~min}$ (Y3) was found to be significant with F-value of 0.0211 implies, the model is significant. The plots are shown in Figs. 11 and 12. The amount of surfactant was mainly responsible for the increase in cumulative percentage of drug released from the formulation. The increase in cumulative drug release was mainly attributed to rapid selfemulsification of the formulations due to instantaneous dispersion in the medium after dissolution of the capsule shell. As the amount of free energy required in the formation of an emulsion is very low, this results in the spontaneous formation of an oil-water interface. This increases the water penetration of oil droplets, resulting in disruption of the interface and thereby decreasing the droplet size and eventually increasing the release rate.

\section{Optimization by desirability function}

An optimization process was undertaken with desirability function to optimize the three responses simultaneously, the results are shown in Table 4. The model was proven to be validated since a fine agreement existed between the predicted and observed results. It can be seen that the experimental values were in very close agreement with the predicted values, indicating the success of the BBD combined with a desirability function for the evaluation and optimization of SNEDDS formulations.

\section{Characterization of SNEDDS}

Developed Ramipril SNEDDSs were physicochemically evaluated in terms of droplet size, ZP, refractive index (RI), and percentage of transmittance $(\% \mathrm{~T})$ for all batches.

\section{Refractive index}

Refractive index, being an optical property, is used to characterize the isotropic nature of nanoemulsion which is to be produce form SNEDDS. The results of all the three batches of confirmed isotropic nature of the systems even after their transformation to nanoemulsions. The RI values of all formulations were in the range of $1.63-1.69$.

\section{Percentage transmittance}

To characterize isotropic nature of SNEDDS, transmittance study was conducted. All the batches have shown nearly $100 \%$ transmittance for all batches. 


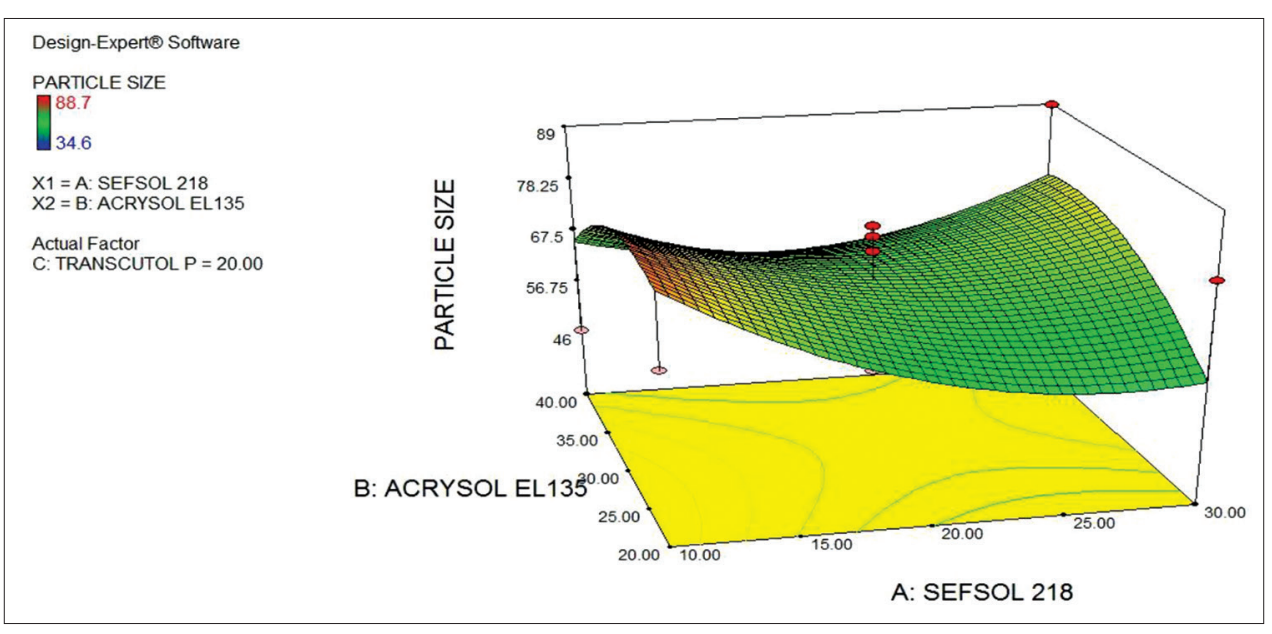

Fig. 7: Contour plot showing the influence of amount of Sefsol 218 and amount of AcrysolEL135 on droplet size fixed level of C

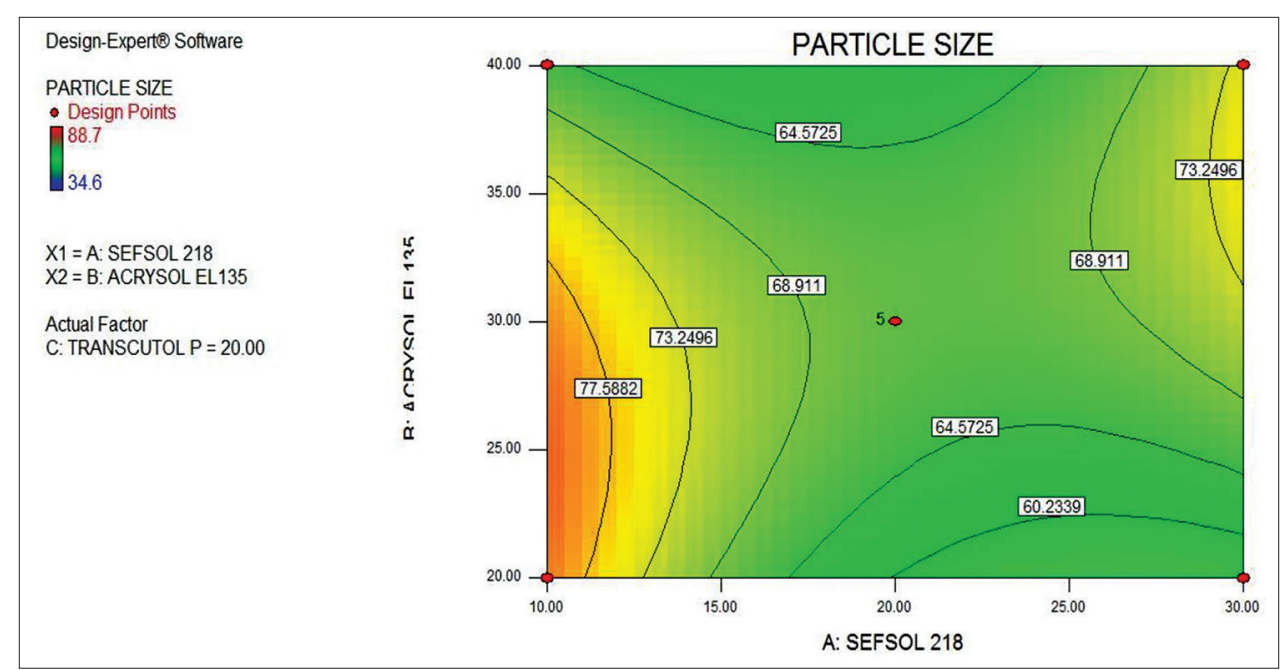

Fig. 8: Contour plot showing the influence of amount of Sefsol 218 and amount of Acrysol EL135 on droplet size fixed level of C

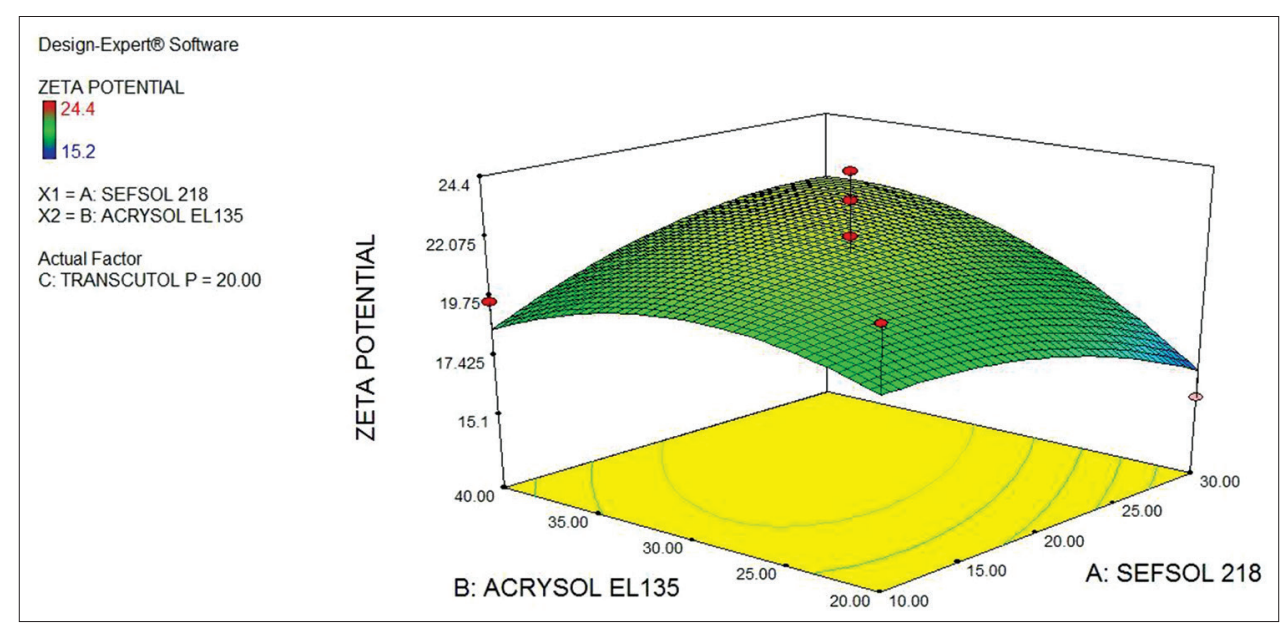

Fig. 9: Response 3D surface plot showing the influence of amount of Sefsol 218 and amount of AcrysolEL135 on Zeta Potential level of C

\section{In vitro dissolution testing of ramipril SNEDDS}

The dissolution profiles of plain Ramipril and Ramipril SNEDDS formulation in simulated intestinal fluid (SIF, pH 6.8) media are presented in Figs. 13-15. The drug release profiles of formulation (RF14) were analyzed. As shown in Fig. 14, more than 85\% of drug was dissolved from RF14 after 60 min. However, the original Ramipril powder showed only approximately $0.7 \%$ dissolved after the same time period. The enhanced dissolution may be due to the decrease in crystallinity and the increase in solubility of the drug. 
Table 4: Optimized values obtained by the constraints applies on Y1, Y2, and Y3

\begin{tabular}{|c|c|c|c|c|c|c|c|c|}
\hline \multirow{2}{*}{$\begin{array}{l}\text { Independent } \\
\text { variable }\end{array}$} & \multicolumn{4}{|c|}{ Predicted values } & \multicolumn{4}{|c|}{ Observed values } \\
\hline & $\begin{array}{l}\text { Nominal } \\
\text { values\% }\end{array}$ & $\begin{array}{l}\text { Droplet size } \\
\text { (Y1) (nm) }\end{array}$ & $\begin{array}{l}\text { Zeta Potential } \\
\text { mV (Y2) }\end{array}$ & $\begin{array}{l}\text { \%CDR } \\
\text { (Y3) }\end{array}$ & Batch & $\begin{array}{l}\text { Droplet size } \\
\text { (Y1) (nm) }\end{array}$ & $\begin{array}{l}\text { Poly-dispersity } \\
\text { index (Y2) }\end{array}$ & $\begin{array}{l}\text { Percent drug release } \\
\text { in } 15 \text { min (Y3) }\end{array}$ \\
\hline $\begin{array}{l}\text { Amount of Sefsol } \\
218(A)\end{array}$ & 10 & 75.3 & -24.4 & 98.65 & 1 & 72.6 & -23.6 & 97.45 \\
\hline $\begin{array}{l}\text { Amount of } \\
\text { AcrysolEL135 (B) }\end{array}$ & 40 & & & & 2 & 76.9 & -23.1 & 98.67 \\
\hline $\begin{array}{l}\text { Amount of } \\
\text { Transcutol P(C) }\end{array}$ & 30 & & & & 3 & 74.6 & -22.8 & 98.14 \\
\hline
\end{tabular}

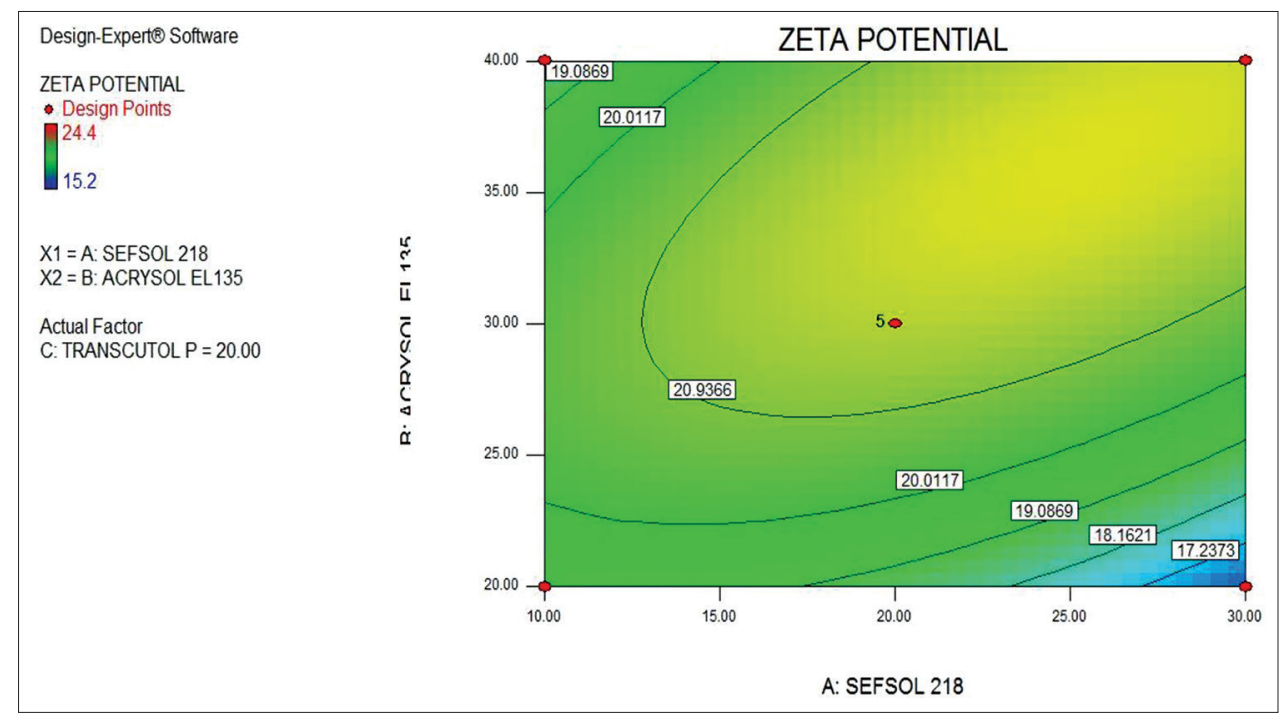

Fig. 10: Contour plot showing the influence of amount of Sefsol 218 and amount of AcrysolEL135 on Zeta Potential level of C further improved by the addition of the cosurfactant

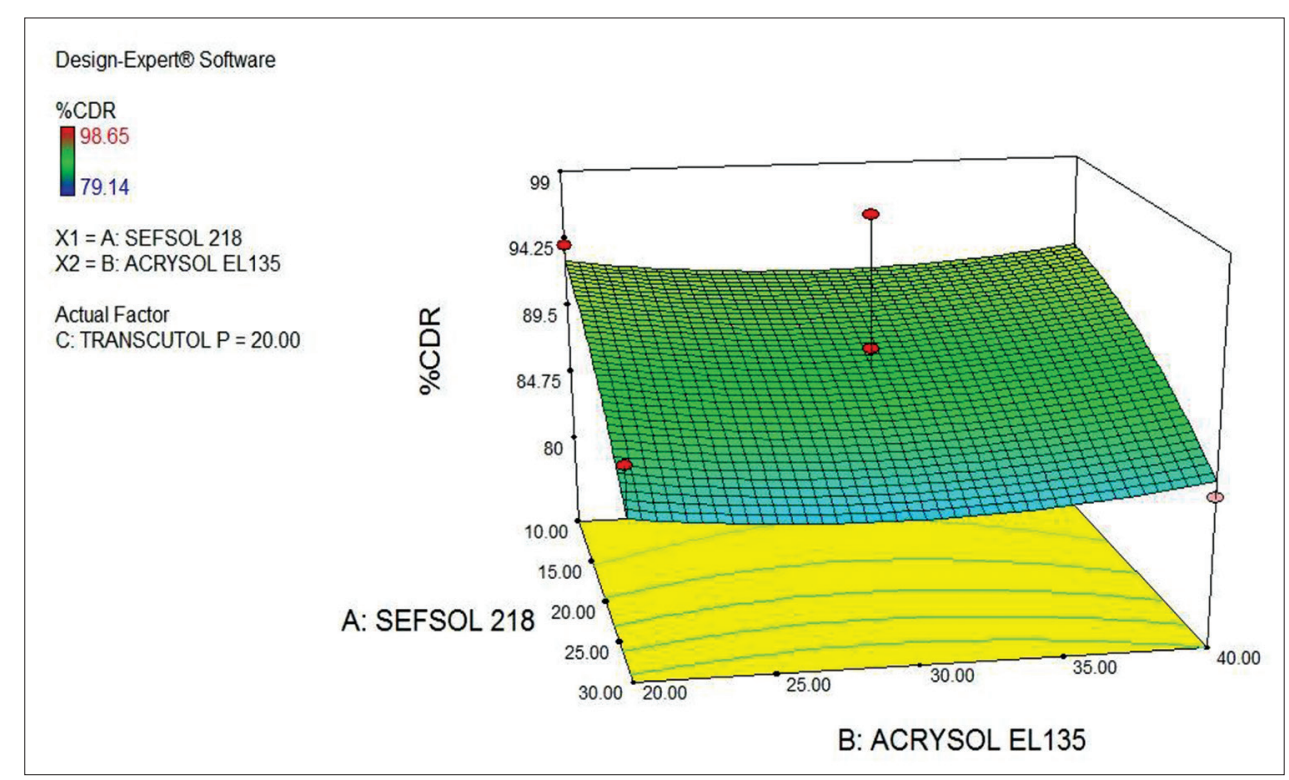

Fig. 11: Response 3D surface plot showing the influence of amount of Sefsol 218 and amount of AcrysolEL135on Cumulative \% Drug Released level of C

\section{Fourier transform infrared (FTIR) studies}

The FTIR spectra of pure Ramipril and optimized formulation (RF14) are shown in Figs. 16 and 17, respectively. The chemical interaction between the drug and excipients often leads to identifiable changes in the infrared profile of dispersion. Drug spectrum shows prominent peaks at IR spectra of Ramipril showing the peaks at $3342.75 \mathrm{~cm}^{-1}$ for $-\mathrm{NH}$ and $-\mathrm{OH}, 2928.04 \mathrm{~cm}^{-1}$ for $-\mathrm{CH}$ aromatic streaching, $1720.56 \mathrm{~cm}^{-1}$ for $-\mathrm{C}=\mathrm{O}$, and $1319.05 \mathrm{~cm}^{-1}$ for- $\mathrm{CH}$ aliphatic bending. The same 


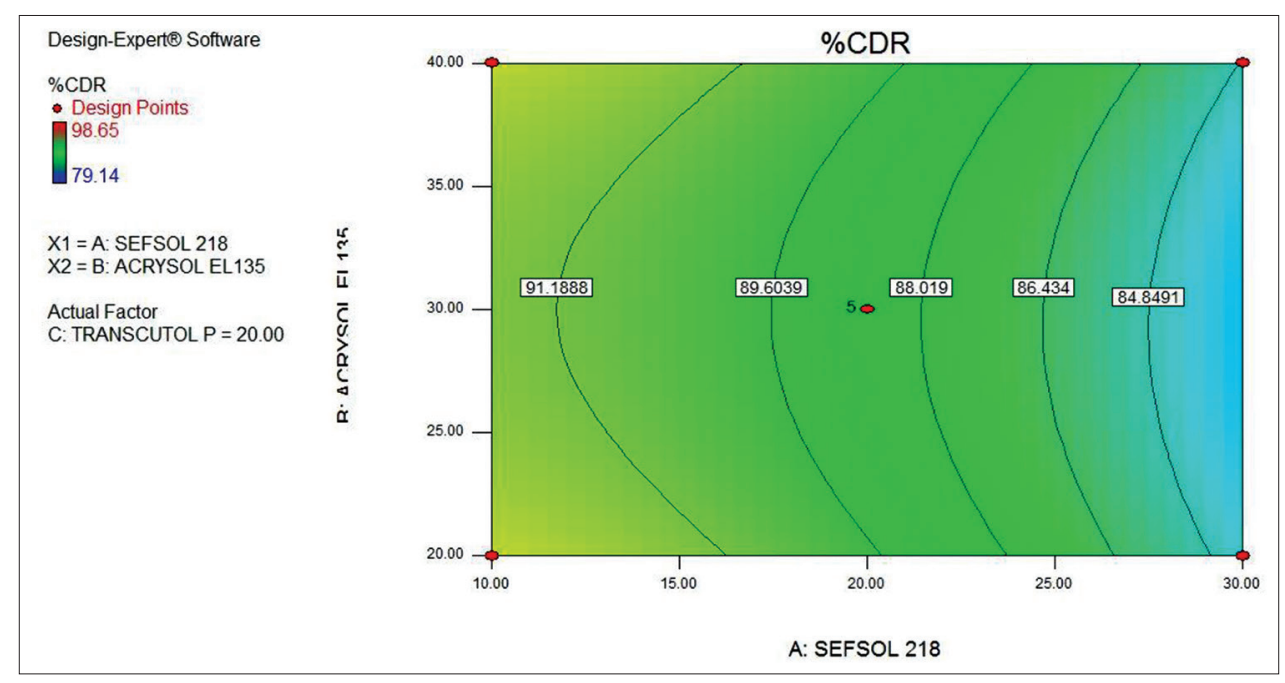

Fig. 12: Contour plot showing the influence of amount of Sefsol 218 and amount of AcrysolEL135 on Cumulative \% Drug Released of C

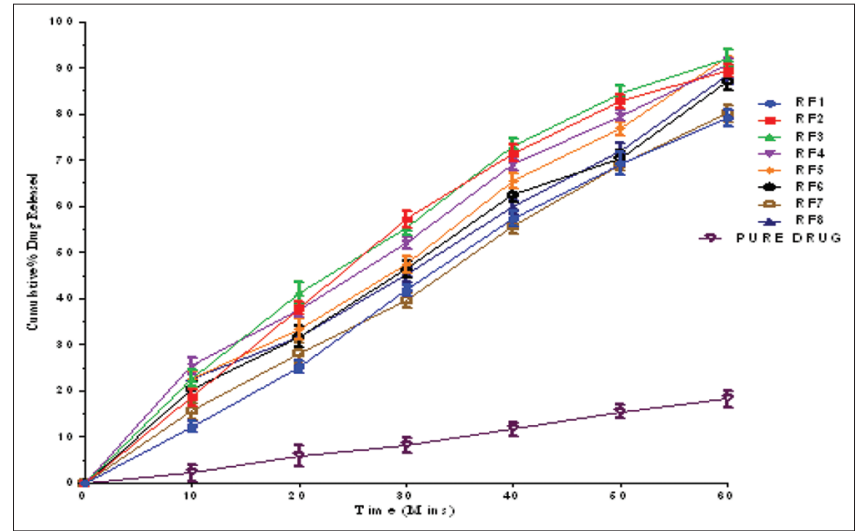

Fig. 13: Comparative dissolution profile of ramipril pure drug and ramipril self-nanoemulsifying drug delivery systems formulation (RF1-RF8)

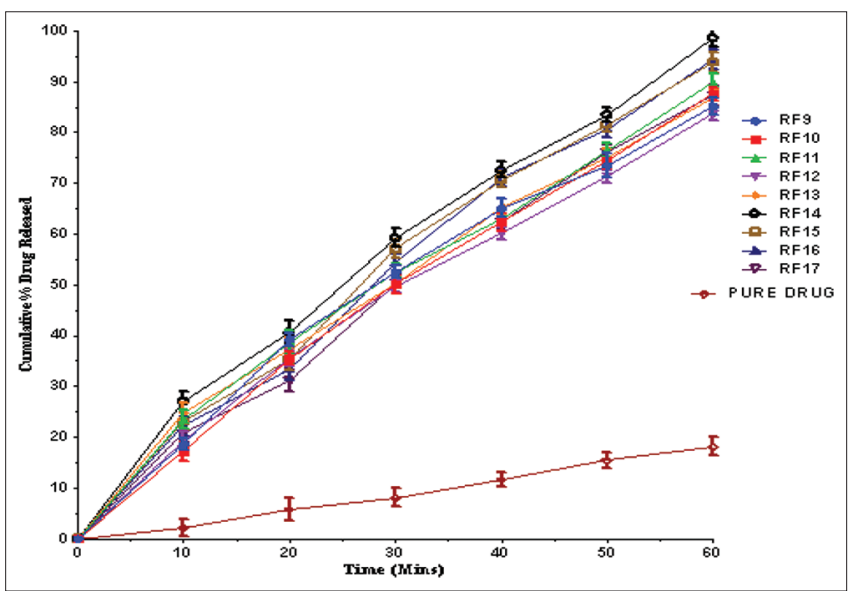

Fig. 14: Comparative dissolution profile of ramipril pure drug and ramipril self-nanoemulsifying drug delivery systems formulation (RF9-RF17)

characteristic peak its slight variations was also noticed in the spectra of optimized formulation.

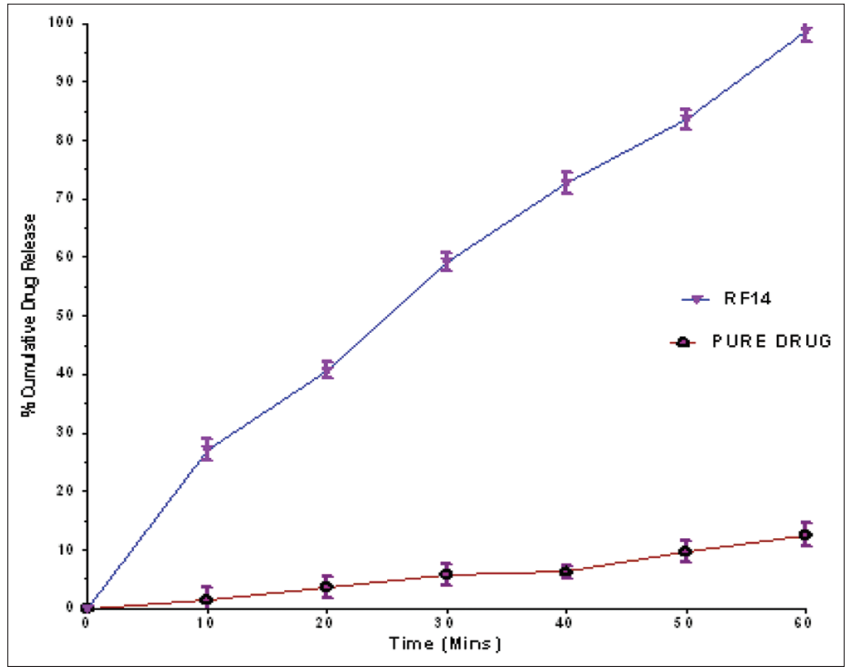

Fig. 15: Comparative in vitro study plot of optimized formulation rf14 and pure drug

Particle size and ZP of optimized formulation

The particle size of the optimized SNEDDS formulation of ramipril (RF14) was found to be $75.3 \mathrm{~nm}$ as shown in Fig. 18. The ZP of the optimized SNEDDS formulation of ramipril (RF14) is found to be $-24.4 \mathrm{mV}$ as shown in Fig. 19.

Scanning electron microscopy (SEM) studies

Morphological and structural examination of the optimized batches of Ramipril loaded SNEDDS (RF14) was carried out using transmission electron microscope. The SEM images illustrated formation of spherical micelles (Figs. 20a and b). These results were in accordance to that of globule size analysis.

\section{Stability study}

There were no physical changes in appearance and flexibility. After subjecting the optimized formulation (RF14) to the accelerated stability studies, the results were shown that there were no major changes in drug EE, in vitro drug release and content uniformity. Hence, the formulation was found to be stable (Table 5).

\section{Pharmacokinetic Studies}

Figs. 21-23 show the plasma concentration-time curve in Wistar rats after a single oral dose of Ramipril SNEDDS formulation as compared 


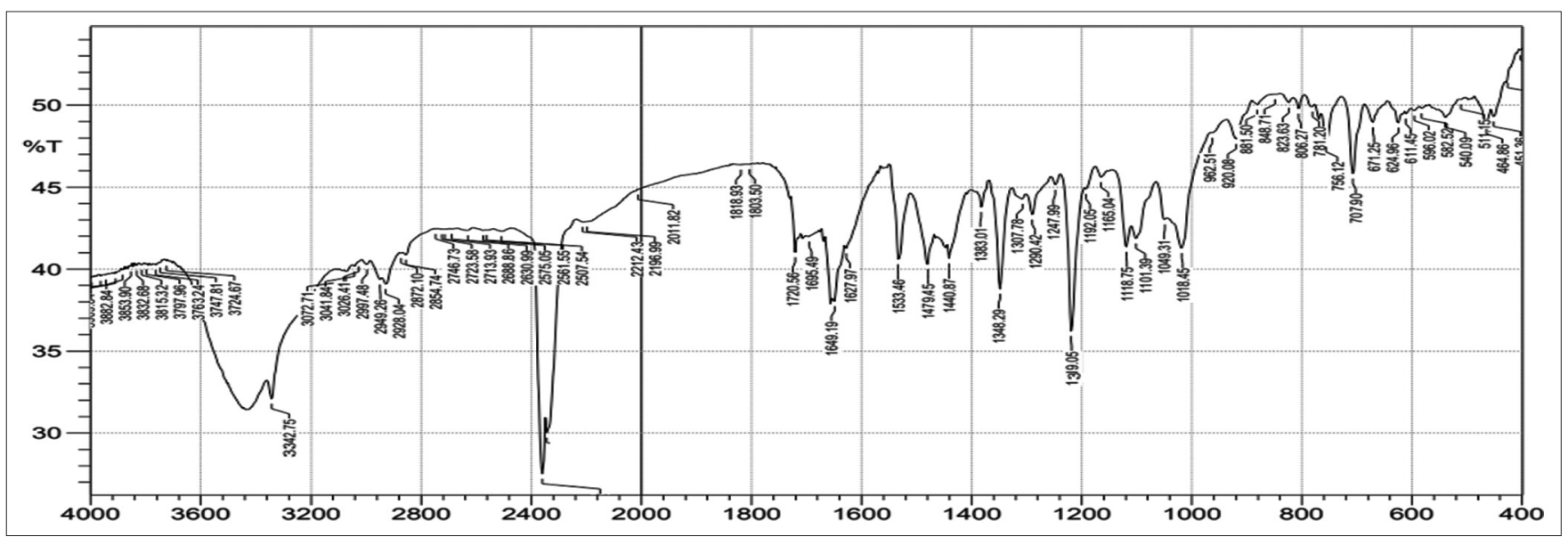

Fig. 16: Fourier transform infrared spectrum of ramipril pure drug

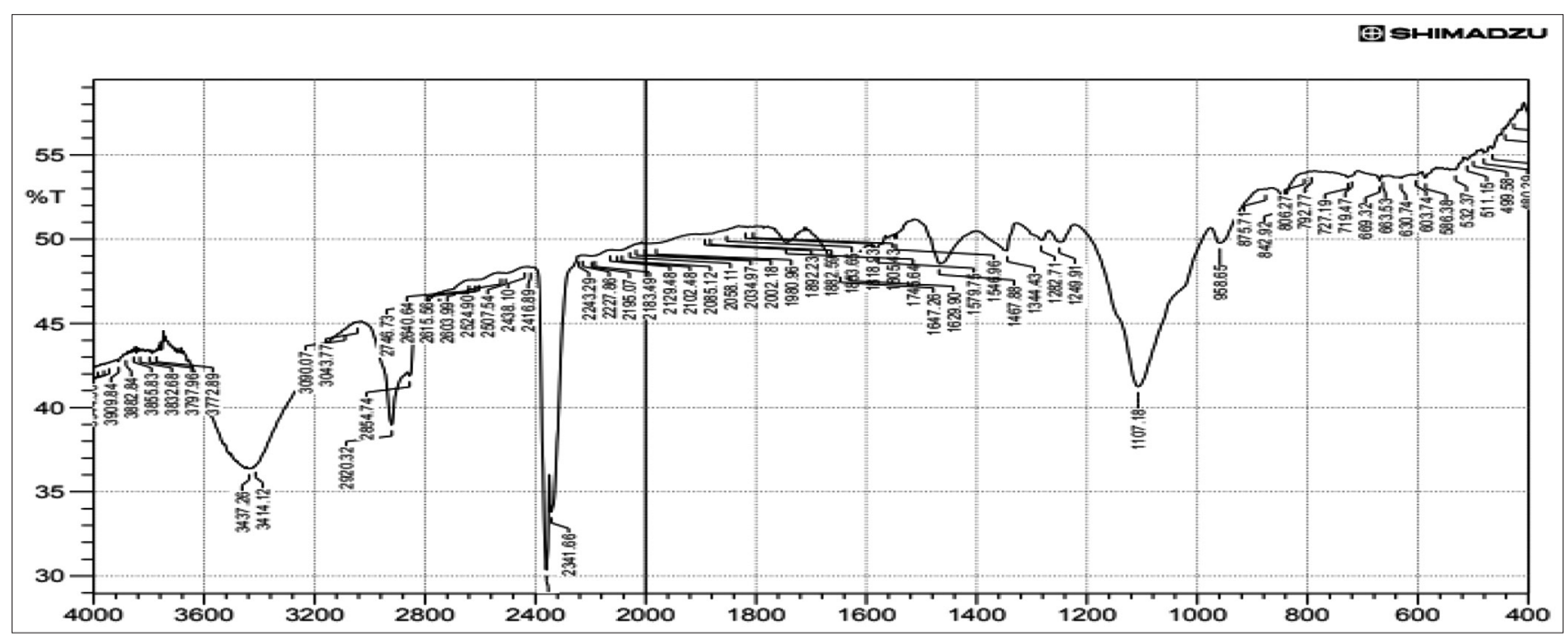

Fig. 17: Fourier transform infrared spectrum of ramipril optimized formulation (RF14)

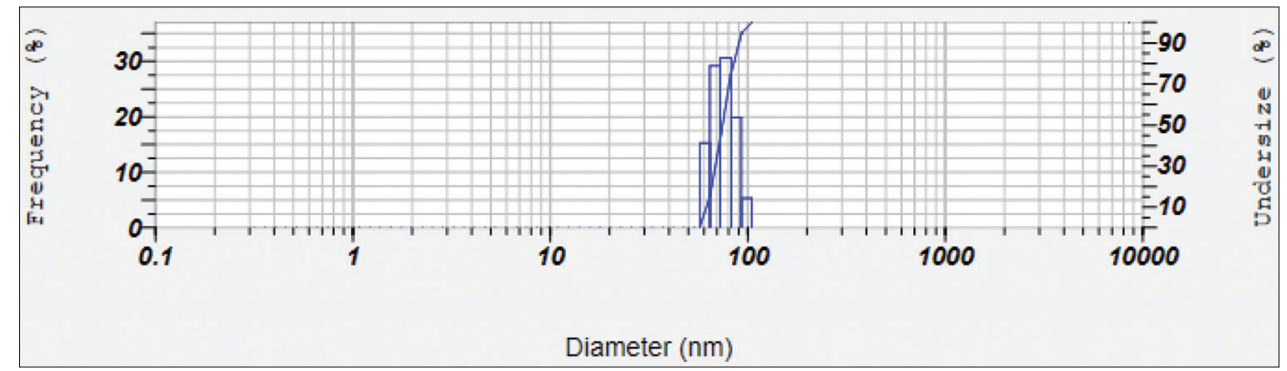

Fig. 18: Particle size of optimized self-nanoemulsifying drug delivery systems of Ramipril (RF14) formulation

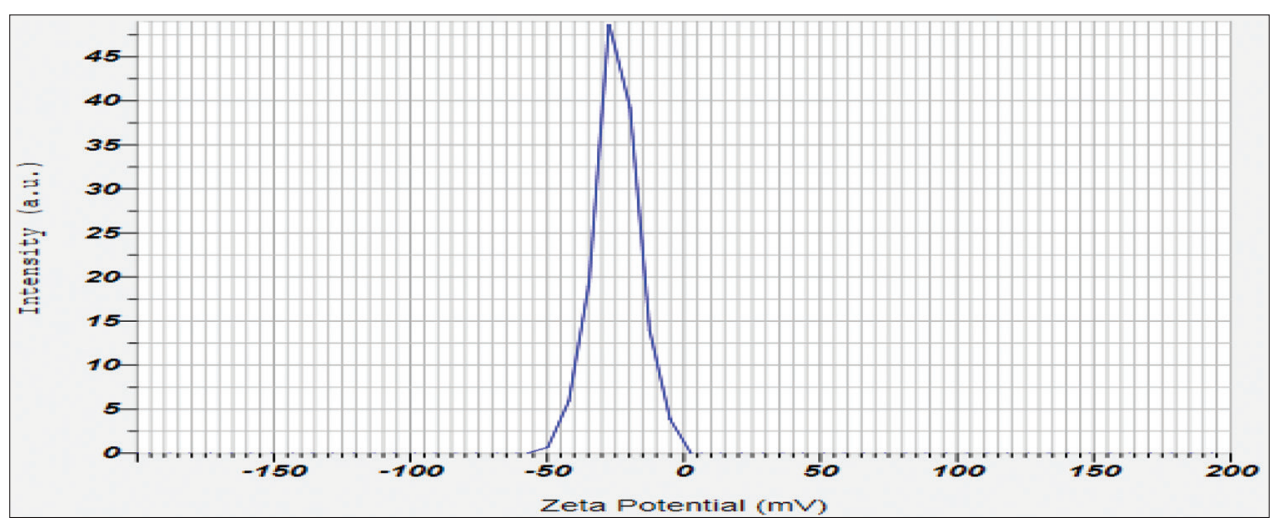

Fig. 19: Zeta potential of optimized self-nanoemulsifying drug delivery systems of Ramipril (RF14) formulation Surface morphology 


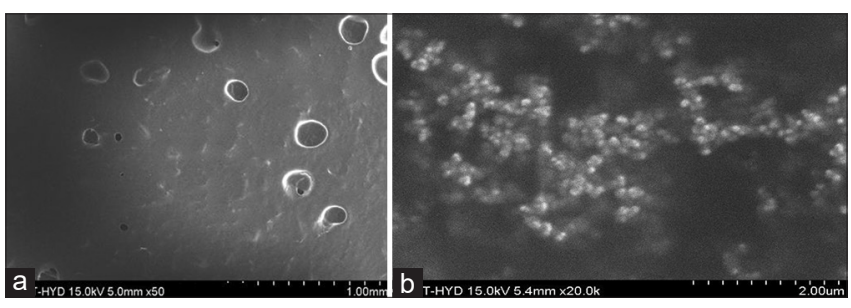

Fig. 20: (a) Scanning electron microscopy (SEM) images of solid lipid nanoparticles of Ramipril (RF14). (b) SEM image of solid lipid nanoparticles of Ramipril (RF14) to Ramipril pure. At all the indicated time points, the Ramipril plasma concentrations in rats treated with SNEDDS formulation were significantly higher than those treated with pure drug. Pharmacokinetic parameters of Ramipril after oral administration of the two formulations in Wistar rats are shown in Table 6.

$\mathrm{C}_{\max }$ of the SNEDDS $25.16 \pm 1.73 \mathrm{ng} / \mathrm{ml}$ was significant $(\mathrm{p}<0.05)$ as compared to the pure drug $8.02 \pm 0.086 \mathrm{ng} / \mathrm{ml}$. Tmax of both SNEDDS formulation and pure drug was $0.5 \pm 0.62$ and $0.5 \pm 0.95 \mathrm{~h}$, respectively. AUC is an important parameter in evaluating bioavailability of drug from dosage form, as it represents the total integrated area under the blood

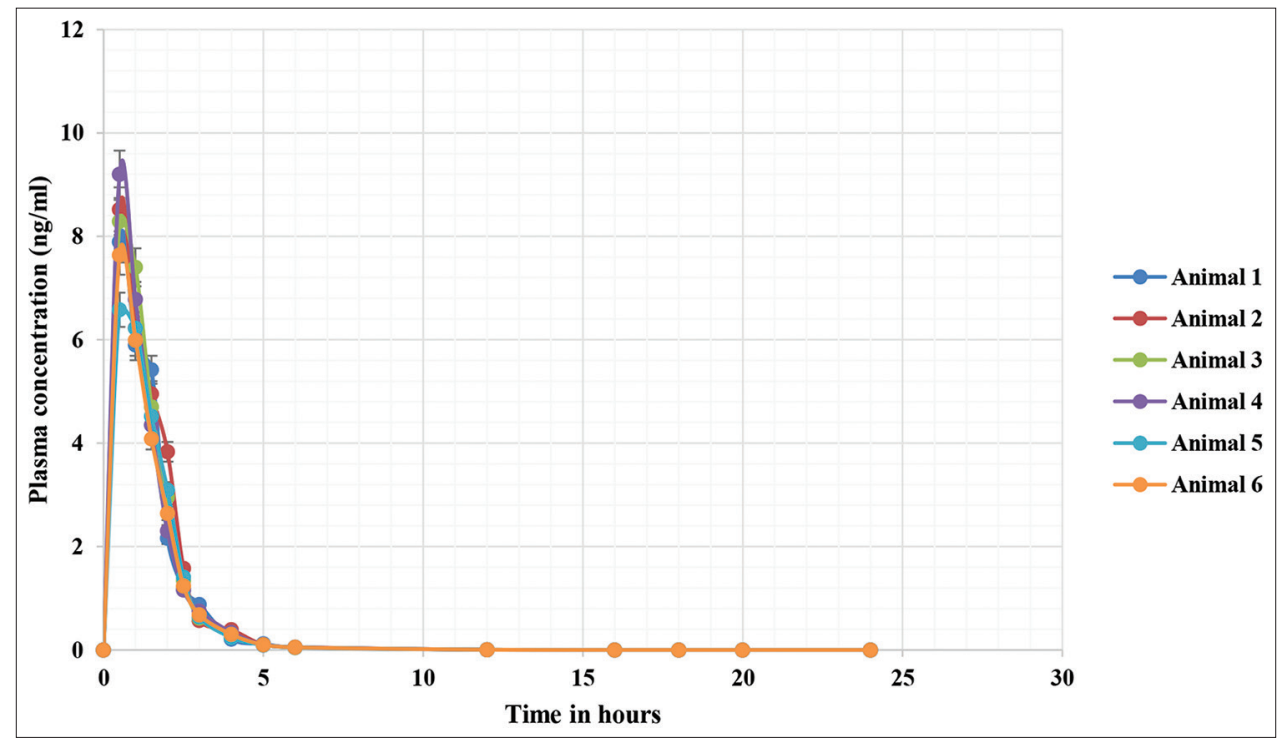

Fig. 21: Plasma concentration-time profile of ramipril pure drug in rat plasma

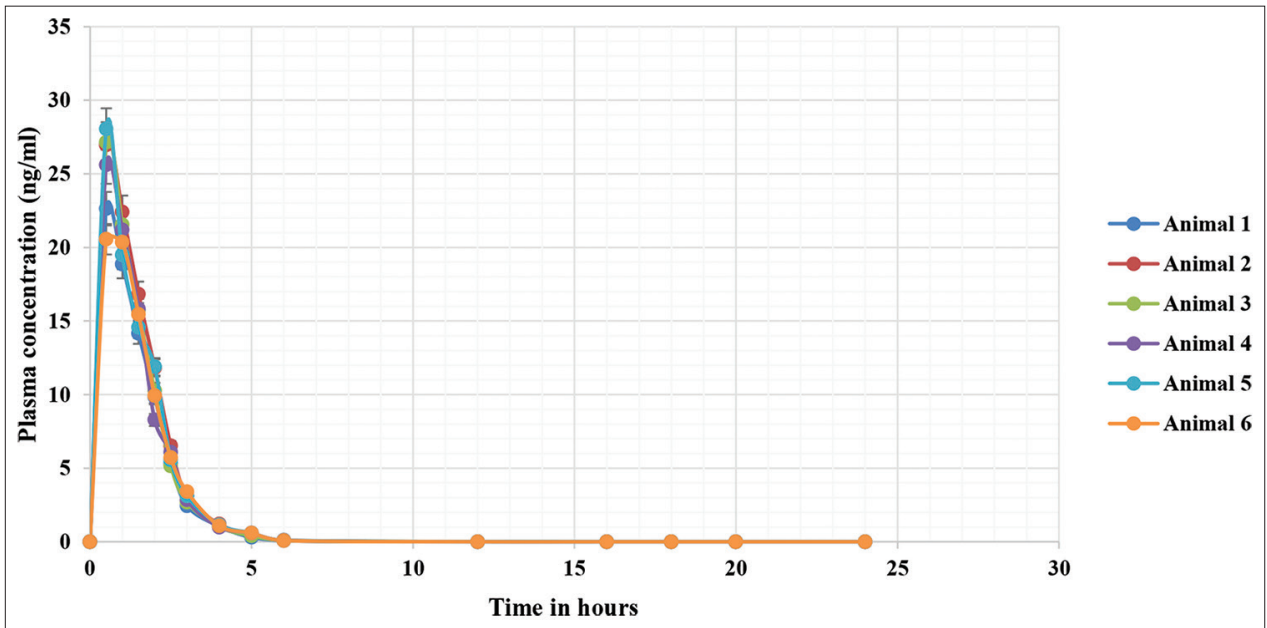

Fig. 22: Plasma concentration-time profile of ramipril optimized self-nanoemulsifying drug delivery systems in rat plasma

Table 5: Parameters after accelerated stability study of optimized formulation RF14

\begin{tabular}{lllll}
\hline Parameters & \multicolumn{2}{l}{$\begin{array}{l}\text { Temperature maintained at } \mathbf{4 0} \mathbf{2 0 C} \\
\text { Relative humidity }\end{array}$} \\
\cline { 2 - 5 } & Initial & After $\mathbf{1}$ month & After 2 months & After $\mathbf{3}$ months \\
\hline Drug entrapment efficiency (\%) & $98.74 \pm 1.97$ & $98.61 \pm 1.53$ & $98.47 \pm 1.42$ & $98.32 \pm 1.35$ \\
In vitro drug release (\%) & $98.64 \pm 1.53$ & $98.57 \pm 1.55$ & $98.42 \pm 1.37$ & $98.31 \pm 1.22$ \\
\#Content uniformity (\%) & $99.52 \pm 1.67$ & $99.43 \pm 1.78$ & $96.29 \pm 1.55$ & $96.17 \pm 1.04$ \\
\hline
\end{tabular}




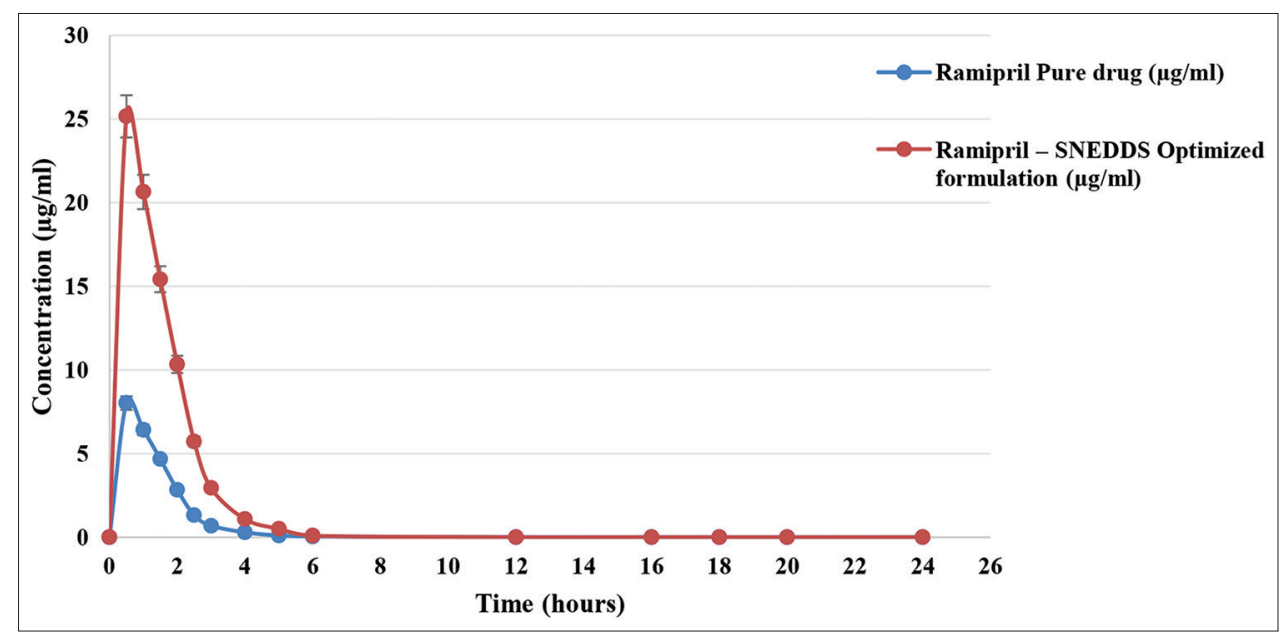

Fig. 23: Mean plasma concentration-time profiles for ramipril pure drug and ramipril optimized self-nanoemulsifying drug delivery systems formulation in rats $(n=6)$

Table 6: Mean pharmacokinetic parameters of ramipril pure drug and ramipril optimized self-nanoemulsifying drug delivery systems formulation

\begin{tabular}{lll}
\hline $\begin{array}{l}\text { Pharmacokinetic } \\
\text { parameters }\end{array}$ & $\begin{array}{l}\text { Ramipril pure } \\
\text { drug }\end{array}$ & $\begin{array}{l}\text { Ramipril optimized self- } \\
\text { nanoemulsifying drug } \\
\text { delivery systems }\end{array}$ \\
\hline $\mathrm{C}_{\max }(\mu \mathrm{g} / \mathrm{ml})$ & $8.02 \pm 0.42$ & $25.16 \pm 1.73$ \\
$\mathrm{AUC0}-\mathrm{t}(\mu \mathrm{g} \cdot \mathrm{h} / \mathrm{ml})$ & $116.57 \pm 1.64$ & $355.49 \pm 1.76$ \\
$\mathrm{AUC} 0$-inf $(\mu \mathrm{g} . \mathrm{h} / \mathrm{ml})$ & $190.46 \pm 1.21$ & $580.93 \pm 1.38$ \\
$\mathrm{Tmax}(\mathrm{h})$ & $0.5 \pm 0.95$ & $0.5 \pm 0.62$ \\
$\mathrm{t} 1 / 2(\mathrm{~h})$ & $14.0 \pm 0.04$ & $12.0 \pm 0.07$ \\
\hline
\end{tabular}

concentration time profile and represents the total amount of drug reaching the systemic circulation after oral administration. AUC0- $\infty$ infinity for SNEDDS formulation was higher $(580.93 \pm 1.38 \mathrm{ng} . \mathrm{h} / \mathrm{ml}$ ) than the pure drug $190.46 \pm 1.21 \mathrm{ng} \mathrm{h} / \mathrm{ml}$. Statistically, AUC0-t of the SNEDDS formulation (355.49 $\pm 1.76 \mathrm{ng} \mathrm{h} / \mathrm{ml}$ ) was significantly higher $(\mathrm{p}<0.05)$ as compared to pure drug $(116.57 \pm 1.64 \mathrm{ng} \mathrm{h} / \mathrm{ml})$. Higher amount of drug concentration in blood indicated better systemic absorption of Ramipril from SNEDDS formulation as compared to the pure drug.

\section{CONCLUSION}

In the present paper, the SNEDDS containing ramipril was successfully prepared employing the SNEDDS formulation. The influence of independent variables on the particle size, PDI, and ZP was evaluated by a BBD. Out of all 17 formulations, the mean particle size, PDI, ZP, $\mathrm{EE}$, content uniformity, and in vitro drug release profile of optimized ramipril-loaded SNEDDS (RF14) were found to be $75.3 \pm 2.21 \mathrm{~nm}$, $0.126 \pm 0.05,-24.4 \pm 5.78 \mathrm{mV}, 98.74 \pm 1.97 \%, 99.52 \pm 1.67 \%$, and $98.65 \pm 1.73 \%$, respectively. The release kinetics suggest that drug release followed zero-order and release from SNEDDS formulation was anomalous non-Fickian diffusion super case II transport. FTIR studies revealed that there is no incompatibility between drug and polymers found, SEM images exhibited nanoparticles to be more porous and in spherical shape. Stability studies indicated that formulation was stable for 6 months. Pharmacokinetic parameters of Ramipril after oral administration of the two formulations in Wistar rats with $\mathrm{C}_{\max }$ of the SNEDDS $25.16 \pm 1.73 \mathrm{ng} / \mathrm{ml}$ compared to the pure drug $8.02 \pm 0.086 \mathrm{ng} / \mathrm{ml}$ and AUC0-t of the SNEDDS formulation

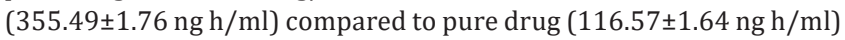
indicated higher amount of drug concentration in blood proving better systemic absorption of Ramipril from SNEDDS formulation as compared to the pure drug.

\section{AUTHOR CONTRIBUTIONS}

Nallapu Jayapal and Yamsani Vamshi Vishnu are contributed equally.

\section{CONFLICT OF INTEREST}

The authors declare no conflict of interest, financial, or otherwise.

\section{REFERENCES}

1. O'Driscoll CM. Lipid-based formulations for intestinal lymphatic delivery. Eur J Pharm Sci 2002;15:405-15.

2. Wu X, Xu J, Huang X, Wen C. Self-microemulsifying drug delivery system improves curcumin dissolution and bioavailability. Drug Dev Ind Pharm 2011;37:15-23.

3. Frampton JE, Peters DH. Ramipril an updated review of its therapeutic use in essential hypertension and heart failure. Drugs 1995;49:440-66.

4. Kalhapure RS, Akamanchi KG. Oleic acid based heterolipid synthesis, characterization and application in self-microemulsifying drug delivery system. Int J Pharm 2012;425:9.

5. Yosra SR, Magda AE, Ossama YA. Self-nanoemulsifying drug delivery systems of tamoxifen citrate: Design and optimization. Int J Pharm 2009;380:133-41.

6. Brusewitz C, Schendler A, Funke A, Wagner T, Lipp R. Novel poloxamer-based nanoemulsions to enhance the intestinal absorption of active compounds. Int J Pharm 2007;329:173-81.

7. Shah SR, Parikh RH, Chavda JR. Self-nanoemulsifying drug delivery system of glimepiride: Design, development, and optimization. PDA J Pharm Sci Tech 2013;67:201-13.

8. Wang X, Michael A, Van den Mooter G. Solid state characteristics of ternary solid dispersions composed of PVP VA64, Myrj 52 and Itraconazole. Int J Pharm 2005;303;54-61.

9. Bandivadekar MM, Pancholi SS, Shelke N. Preparation and characterization of solid SMEDDS by adsorbent techniques to improve dissolution profile of poorly aqueous soluble drug Ramipril. Int Res J Pharm 2011;2:85-90.

10. Ping Z, Ying L, Nianping F, Jie X. Preparation and evaluation of self-microemulsifying drug delivery system of oridonin. Int J Pharm 2008;355:269-76.

11. Grove M. Bioavailability of seocalcitol II: Development and characterization of self-microemulsifying drug delivery systems (SMEDDS) for oral administration containing medium and long chain triglycerides. Eur J Pharm Sci 2004;28:233-42.

12. Zhang P, Liu Y, Feng N, Xu J. Preparation and evaluation of self microemulsifying drug delivery system of oridonin. Int $\mathrm{J}$ Pharm 2008;355:269-76.

13. Parmar K, Patel J, Sheth N. Self-nano-emulsifying drug delivery system for Embelin: Design, characterization and in-vitro studies. Asian J Pharm Sci 2015;10:396-404.

14. Zhang J, Peng Q, Shi S, Zhang Q, Sun X, Gong T, et al. Preparation, characterization, and in vivo evaluation of a self-nano emulsifying drug 
delivery system (SNEDDS) loaded with morin-phospholipid complex. Int J Nanomed 2011;6:3405-16.

15. Basaran E, Demirel M, Sirmagul B. Cyclosporinea incorporated cationic solid lipid nanoparticles for ocular delivery. J Microencapsul
2010;27:37-47.

16. Pereira A, Gadad AP, Patil AS, Dandagi PM. Development and bioavailability assessment of ramipril nanoparticle formulation. Indian J Pharm Educ Res 2019;54:s587-95. 